\title{
UCRL-CONF-213295
}

LAWRENCE LIVERMORE N A T IO N A L LABORATORY

\section{Compatibility of the Radiating Divertor with High Performance Plasmas in DIII-D}

T.W. Petrie, M.R. Wade, S.L. Allen, N.H. Brooks, M.E.

Fenstermacher, J.R. Ferron, C.M. Greenfield, M. Groth, A.W. Hyatt, C.J. Lasnier, A.W. Leonard, T.C. Luce, M.A. Mahdavi, M.J. Schaffer, J.G. Watkins, W.P. West

June 28, 2005

32nd EPS Plasma Physics Conference

Tarragona, Spain

June 27, 2005 through July 1, 2005 
This document was prepared as an account of work sponsored by an agency of the United States Government. Neither the United States Government nor the University of California nor any of their employees, makes any warranty, express or implied, or assumes any legal liability or responsibility for the accuracy, completeness, or usefulness of any information, apparatus, product, or process disclosed, or represents that its use would not infringe privately owned rights. Reference herein to any specific commercial product, process, or service by trade name, trademark, manufacturer, or otherwise, does not necessarily constitute or imply its endorsement, recommendation, or favoring by the United States Government or the University of California. The views and opinions of authors expressed herein do not necessarily state or reflect those of the United States Government or the University of California, and shall not be used for advertising or product endorsement purposes. 


\title{
Compatibility of the Radiating Divertor With High Performance Plasmas in DIII-D
}

\author{
T.W. Petrie ${ }^{1}$, M.R. Wade ${ }^{1}$, S.L. Allen ${ }^{2}$, N.H. Brooks ${ }^{1}$, M.E. Fenstermacher ${ }^{2}$, J.R. Ferron ${ }^{1}$, \\ C.M. Greenfield ${ }^{1}$, M. Groth ${ }^{2}$, A.W. Hyatt ${ }^{1}$, C.J. Lasnier ${ }^{2}$, A.W. Leonard ${ }^{1}$, T.C. Luce ${ }^{1}$, \\ M.A. Mahdavi ${ }^{1}$, M.J. Schaffer ${ }^{1}$, J.G. Watkins ${ }^{3}$, W.P. West ${ }^{1}$, and the DIII-D Team \\ ${ }^{1}$ General Atomics, P.O. Box 85608, San Diego, California 92186-5608, USA \\ ${ }^{2}$ Lawrence Livermore National Laboratory, Livermore, California, USA \\ ${ }^{3}$ Sandia National Laboratories, Albuquerque, New Mexico, USA
}

Excessive thermal power loading on the divertor structures presents a design difficulty for future-generation, high powered tokamaks. This difficulty may be mitigated by "seeding" the divertor with impurities which radiate a significant fraction of the power upstream of the divertor targets. For this "radiating divertor" concept to be practical, however, the confinement and stability of the plasma cannot be compromised by excessive leakage of the seeded impurities into the core plasma. One proposed way of reducing impurity influx is to enhance the directed scrape-off layer (SOL) flow of deuterium ions toward the divertor [1-5].

We report here on the successful application of the radiating divertor scenario to high performance plasma operation in a DIII-D "hybrid" H-mode regime. The "hybrid" regime [6,7] has many features in common with conventional ELMing H-mode regimes, such as high confinement, e.g., $\mathrm{H}_{\text {ITER89P }}>2$, where $\mathrm{H}_{\text {ITER89P }}$ is the energy confinement normalized to the 1989 ITER L-mode scaling [8]. The main difference is the absence of sawtooth activity in the hybrid. Argon was selected as the seeded impurity for this experiment because argon radiates effectively at both the divertor and pedestal temperatures found in DIII-D hybrid $\mathrm{H}$-mode operation and has a relatively short ionization mean free path. Carbon is also present as the dominant intrinsic impurity in DIII-D discharges.

The geometry of this experiment is shown in Fig. 1. A double-null cross-sectional shape was biased upward $(\mathrm{dRsep}=+1.0 \mathrm{~cm})$. To increase the deuterium ion flow toward the divertor at the top of the vessel, deuterium gas was introduced near the bottom. Argon was injected directly into the private flux region (PFR) of the upper divertor. In-vessel pumping of deuterium and argon was done by cryopumps located in the two upper divertor plenums, shown in cross-hatching [9]. The upper divertor, which we hereafter will simply refer to as the "divertor", is the region lying above the dashed line in Fig. 1, and is relatively "closed."

The global parameters in this experiment were: plasma current $I_{p}=1.2 \mathrm{MA}$, toroidal field $B_{T}=1.8 \mathrm{~T}$ with the $\boldsymbol{B} \times \nabla B$ ion drift directed downward, $q_{95}=4.3$,

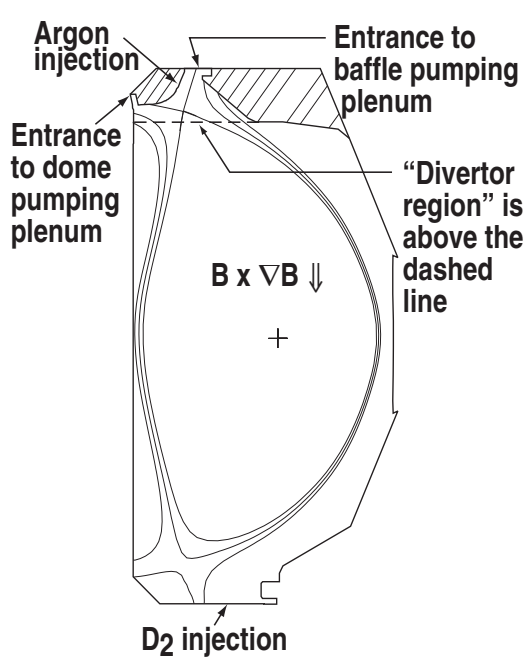

Fig. 1. Particle pumping- and gas injection locations are superimposed on the plasma cross-section. The "divertor region" lies above the dashed line. 
power input $P_{I N}=(5-7) \mathrm{MW}$, line-averaged density $n_{e, \text { ave }}=(0.4-0.7) \times 10^{20} \mathrm{~m}^{-3}$ (or $\mathrm{n}_{\mathrm{e}, \text { ave }}$ )

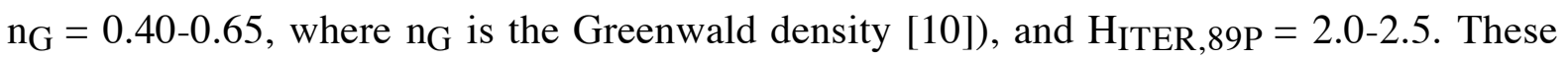
discharges, operating in the Type-1 ELMing regime, had stationary-state phases lasting $>3 \mathrm{~s}$.

A measure of how well the injected argon is preferentially confined to the divertor is the exhaust enrichment: $\eta_{\mathrm{EXH}} \equiv \mathrm{f}_{\mathrm{EXH}} / \mathrm{f}_{\mathrm{core}}$, where $\mathrm{f}_{\mathrm{EXH}}$ is the ratio of the neutral argon pressure in the baffle plenum to the atomic-equivalent pressure of deuterium, and $\mathrm{f}_{\text {core }}$ is the ratio of impurity density to electron density. Absolute measurements of the spatial profiles of He-like argon and fully-stripped carbon in the core plasma were made using charge-exchange recombination spectroscopy [11]. A Penning gauge made simultaneous measurement of the partial pressures of argon and deuterium in the exhaust gas [12].

For trace argon injection, the argon concentration $\mathrm{f}_{\mathrm{AR} \text {, core }}\left(\mathrm{n}_{\mathrm{AR}} / \mathrm{n}_{\mathrm{e}}\right.$ at radial location $\rho=$ 0.7) was determined for three deuterium injection rates $\Gamma_{\mathrm{D} 2}$ (Table 1). We chose $\rho=0.7$, because the MIST [13] impurity transport analysis of these plasmas indicated that helium-like argon at $\rho \approx 0.7$ was by far the dominant charge state of argon and was thus a good approximation for the total argon density; $\rho=0.7$ is located $10 \mathrm{~cm}$ inboard of the outer midplane separatrix. When $\Gamma_{\mathrm{D} 2}$ was increased, $\mathrm{f}_{\mathrm{AR}}$,core decreased while $\eta_{\mathrm{EXH}}$ rose proportionately with $\Gamma_{\mathrm{D} 2}$. The ELM frequency $\left(v_{\mathrm{ELM}}\right)$ also increased with $\Gamma_{\mathrm{D} 2}$.

Table 2 summarizes the response of the hybrid plasmas to changes in the argon injection rate $\left(\Gamma_{\mathrm{AR}}\right)$ at radiatively significant levels; $\Gamma_{\mathrm{D} 2}$ was the same for the three cases. When the "high" $\Gamma_{\mathrm{AR}}($ Case 3$)$ is compared with the trace $\Gamma_{\mathrm{AR}}$ (Case 1), we find for the high $\Gamma_{\mathrm{AR}}$ case that: (1) The total radiated power fraction $\mathrm{P}_{\mathrm{Rad}, \text { tot }} / \mathrm{P}_{\mathrm{IN}}$ increased from 0.46 to 0.62 , and both core radiation $\mathrm{P}_{\mathrm{Rad} \text {,core }}$ and divertor radiation $\mathrm{P}_{\mathrm{Rad} \text {,div }}$ increased by about the same amount, (2) The normalized peak heat flux at the outer diverter target $\mathrm{Q}_{\text {peak }} / \mathrm{Q}_{\text {peak, } 1}$ fell by $\approx 40 \%$, where the peak heat flux has been normalized to Case 1, and (5) The Type-I ELM (frequency $\left(v_{\text {ELM }}\right)$ was unchanged at $\approx 70 \mathrm{~Hz}$. Electron temperature at the outer divertor target decreased from $\approx 15 \mathrm{eV}$ (Case 1) to $\approx 9 \mathrm{eV}$ (Case 3), and both inner and outer divertor legs were "attached" during argon injection in all three cases.

While the core carbon concentration $\mathrm{n}_{\mathrm{C}} / \mathrm{n}_{\mathrm{e}}$ was almost unchanged for Cases $1-3$, the absolute amount of carbon was slightly higher in Case 3 than in Case 1. An increase

Table 1. Trace argon injection at three levels of deuterium injection

\begin{tabular}{|l|c|c|c|}
\hline & Case A & Case B & Case C \\
\hline$\Gamma_{\mathrm{D} 2}\left(\right.$ particles $\left./ \mathrm{s} \times 10^{21}\right)$ & 0 & 3.4 & 7.1 \\
\hline$\Gamma_{\mathrm{AR}}\left(\right.$ particles $\left./ \mathrm{s} \times 10^{19}\right)$ & 1.3 & 1.3 & 1.3 \\
\hline $\mathrm{n}_{\mathrm{AR}} / \mathrm{n}_{\mathrm{e}}(\rho=0.7)(\%)$ & 0.092 & 0.034 & 0.013 \\
\hline$\eta_{\mathrm{EXH}}$ & 11.4 & 24.3 & 35.1 \\
\hline $\mathrm{n}_{\mathrm{e}, \text { ave }}\left(10^{20} \mathrm{~m}^{-3}\right)$ & 0.47 & 0.58 & 0.61 \\
\hline$v_{\mathrm{ELM}}$ & 40 & 55 & 70 \\
\hline
\end{tabular}

Table 2. Three levels of argon injection at fixed deuterium injection

\begin{tabular}{|c|c|c|c|}
\hline $\begin{array}{l}\text { Note: } \beta_{\mathrm{N}} \approx 2.4 \\
\text { in All Cases }\end{array}$ & $\begin{array}{c}\mathrm{D}_{2}+\text { Argon } \\
\text { (Case 1) }\end{array}$ & $\begin{array}{c}\mathrm{D}_{2}+\text { Argon } \\
\text { (Case 2) }\end{array}$ & $\begin{array}{l}\mathrm{D}_{2}+\text { Argon } \\
\text { (Case 3] }\end{array}$ \\
\hline$\Gamma_{\mathrm{D} 2}$ (particles/s $\times 10^{21}$ ) & 7.1 & 7.1 & 7.1 \\
\hline$\Gamma_{\mathrm{AR}}\left(\right.$ particles $\left./ \mathrm{s} \times 10^{19}\right)$ & 1.3 & 11.3 & 21.3 \\
\hline$n_{e, a v e}\left(10^{20} m^{-3}\right)$ & 0.61 & 0.64 & 0.67 \\
\hline HITER 89P & 1.9 & 2.0 & 2.0 \\
\hline$P_{\text {IN }}(M W)$ & 6.9 & 6.8 & 6.6 \\
\hline$P_{\text {Rad,tot }} / P_{\text {IN }}$ & 0.46 & 0.53 & 0.62 \\
\hline $\mathbf{P}_{\text {Rad,cor }} / \mathbf{P}_{\mathrm{IN}}$ & 0.17 & 0.20 & 0.24 \\
\hline $\mathbf{P}_{\text {Rad,div }} / P_{\text {IN }}$ & 0.15 & 0.18 & 0.21 \\
\hline$Q_{\text {Peak }} / Q_{\text {Peak,1 }}$ & 1.0 & - & 0.58 \\
\hline$v_{\text {ELM }}(\mathrm{Hz})$ & $\approx 70$ & $\approx 70$ & $\approx 70$ \\
\hline$n_{e}(\rho=0.7)\left(10^{20} m^{-3}\right)$ & 0.52 & 0.53 & 0.55 \\
\hline$n_{c} / n_{e}(\rho=0.7)(\%)$ & 2.9 & 3.1 & 3.0 \\
\hline $\mathrm{n}_{\mathrm{AR}} / \mathrm{n}_{\mathrm{e}}(\rho=0.7)(\%)$ & 0.013 & 0.10 & 0.19 \\
\hline$Z_{\text {eff }}[\rho=0.7]$ & 1.9 & 2.2 & 2.4 \\
\hline$\eta_{\text {EXH }}$ & 35.1 & 35.1 & 34.4 \\
\hline
\end{tabular}


in $\Gamma_{\mathrm{AR}}$ led to a pronounced increase in both $\mathrm{n}_{\mathrm{AR}} / \mathrm{n}_{\mathrm{e}}$ and core $\mathrm{Z}_{\mathrm{eff}}$, the latter almost entirely due to the additional argon in the core. $\Gamma_{\mathrm{AR}}$ for Case 3 was about 16 times that of Case 1 , and $\mathrm{n}_{\mathrm{AR}}$ for Case 3 was also about 16 times that of Case 1 . Hence, for $\Gamma_{\mathrm{AR}} \leq 2.1 \times 10^{20}$ particles/s, $\mathrm{n}_{\mathrm{AR}} \propto \Gamma_{\mathrm{AR}}$, while $\eta_{\mathrm{EXH}}$ was insensitive to $\Gamma_{\mathrm{AR}}$. This contrasts with a previous study done in a more open DIII-D divertor, where $\eta_{\text {EXH }}$ decreased markedly at higher levels of $\Gamma_{\mathrm{AR}}[4]$.

The radiated power profiles for the three cases in Table 2 are shown in Fig. 2. With only a trace amount of argon in the core, the radiated power profile was predominantly due to carbon. Using measured $\mathrm{n}_{\mathrm{e}}, \mathrm{T}_{\mathrm{e}}, \mathrm{n}_{\mathrm{AR}}$, and radiated power plus the radiation emission rates for argon [14], we estimate that more than $70 \%$ of the increase in radiated power between trace and high $\Gamma_{\mathrm{AR}}$ cases was due to argon. Yet, the primary radiator inside the core plasma remained carbon in all cases. For even the high $\Gamma_{\mathrm{AR}}$ case, the fraction of the radiated power due to argon was only about one-quarter of the total radiated power from the core.

Approximately $40 \%$ of the increase in $P_{\text {Rad,tot }}$ between the trace and high $\Gamma_{\mathrm{AR}}$ cases was in the core and another $\approx 40 \%$ was in the divertor. The other $20 \%$ was in the SOL. Figures 3(a,b) show similarities in the distribution of divertor radiated power for both cases. There were three localized regions of peaked emissivity: along the inboard divertor leg, along the outboard baffle, and near the outer divertor target. The main difference in the radiation distribution in the divertor was

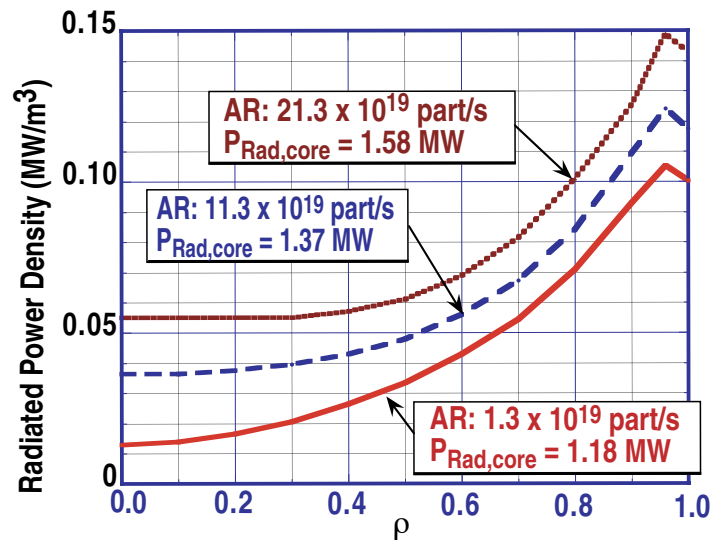

Fig. 2. The radiated power densities for the three $\mathrm{D}_{2}+$ argon injection cases are plotted as a function of normalized radial coordinate $\rho$. that the peak emissivity near the outer divertor target was $\approx 2.5 \mathrm{x}$ higher for the high $\Gamma_{\mathrm{AR}}$ case than for the trace case.

Separate measurements of the radiated power due to argon, carbon, and deuterium were not available for the divertor. Still inferences from available spectroscopic and bolometric data can be drawn. Since little argon was present in Case 1, $\mathrm{P}_{\mathrm{Rad}, \mathrm{div}}$ would have to be from carbon and/or deuterium. Since both divertor legs were attached and $\mathrm{T}_{\mathrm{e}} \approx 15 \mathrm{eV}$ at the divertor targets, the peaks in deuterium emissivity would be localized at or near the inner and outer divertor targets, and this was confirmed by the camera monitoring $D_{\alpha}(656.3 \mathrm{~nm})$ radiation in the divertor. The CIII $(465 \mathrm{~nm})$ radiation in the divertor was monitored by a second camera. Divertor spectroscopy has shown previously that CIII emission is a good indicator of the location of the dominant radiator CIV lines. In contrast with deuterium, the CIII inversions display distribution much more consistent with the bolometric inversions. We thus infer that $\mathrm{P}_{\mathrm{Rad}, \mathrm{div}}$ was predominantly from carbon.

We also infer that carbon must be the main radiator in the divertor at high $\Gamma_{\mathrm{AR}}$. The CIII inversions for trace and high $\Gamma_{\mathrm{AR}}$ cases are similar, suggesting no major change in the carbon radiated power. The CII $(514.7 \mathrm{~nm})$ inversions, representing a kind of "carbon source" distri- 
bution in the divertor, shows little change across most of the divertor, except for a $50 \%$ increase in the CII signal at the outer divertor target in the high $\Gamma_{\mathrm{AR}}$ case. At the outer divertor target, both the ARII (433.1 nm) signal and the CII signal are proportional to $\Gamma_{\mathrm{AR}}$, suggesting the possibility of carbon sputtering by argon, which could be facilitated by the combination of a large thermal deuterium flux at the target with the impinging argon ions [15]. Assuming the entire increase in divertor radiation between trace

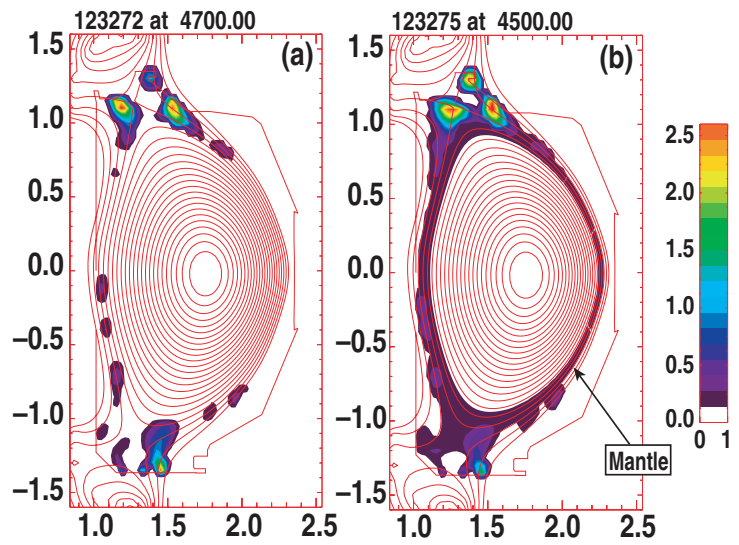

Fig. 3. Tomographic inversions of bolometer data show the poloidal distribution of the radiated power density for (a) Case 1 and (b) Case 3. and high $\Gamma_{\mathrm{AR}}$ cases were due to argon, an upper bound on the ratio of the argon contribution to the total divertor radiation in the high $\Gamma_{\mathrm{AR}}$ case is $\approx 0.29$, which would be about twice the measured value reported in [4].

This experiment was the first attempt at melding a radiating divertor scenario with a high performance hybrid plasma. Argon puffing into the PFR in combination with $\mathrm{D}_{2}$ injection into the SOL was effective in reducing power loading at the divertor targets by raising $\mathrm{P}_{\mathrm{Rad}, \text { core }}$ and $\mathrm{P}_{\mathrm{Rad} \text {,div }}$ in near proportionality to $\Gamma_{\mathrm{AR}}$ over the range in $\Gamma_{\mathrm{AR}}$ studied. The insensitivity of $\eta_{\mathrm{EXH}}$ to $\Gamma_{\mathrm{AR}}$ at fixed $\Gamma_{\mathrm{D} 2}$ suggests that the plasma could have tolerated even higher levels $\Gamma_{\mathrm{AR}}$ while still maintaining acceptable hybrid performance. Moreover, the linear response of $P_{R a d, c o r e}$ and $P_{\text {Rad,div }}$ to $\Gamma_{A R}$ suggests that feedback control of $\Gamma_{A R}$ to maximize the radiated power should be possible, as proposed earlier in [4].

A clear tradeoff exists between desirable reduction in heat flux from enhanced radiated power and unfavorable fuel ion displacement in the core plasma by the argon. Argon accumulation in the core may be ameliorated by increasing $\Gamma_{\mathrm{D} 2}$. We also note that, even in the high $\Gamma_{\mathrm{AR}}$ case and without sawteeth present, the radiated power profile is not peaked on axis. Whether or not this means that the hybrid plasma can "naturally" resist the accumulation of impurities on axis without sawteeth will be the subject of future investigation.

This work was supported by the U.S. Department of Energy under DE-FC0204ER54698, W-7405-ENG-48, and DE-AC04-94AL85000.

[1] M.J. Schaffer, et al., Nucl. Fusion 35 (1995) 1000.

[2] M.J. Schaffer, et al., J. Nucl. Mater. 241-243 (1997) 585.

[3] M.R. Wade, et al., Nucl. Fusion 38 (1998) 1839.

[4] M.R. Wade, et al., J. Nucl. Mater. 266-269 (1999) 44.

[5] J.A. Goetz, et al., J. Nucl. Mater. 266-269 (1999) 359.

[6] T.C. Luce, et al., Nucl. Fusion 43 (2003) 321.

[7] M.R. Wade, et al., Proc. 20th IAEA Fusion Energy Conf., Vilamoura, Portugal, 2004.

[8] P.N. Yushmanov, et al., Nucl. Fusion 30 (1990) 1999.

[9] T.W. Petrie, et al., J. Nucl. Mater. 337-339 (2005) 216.

[10] M. Greenwald, et al., Nucl. Fusion 28 (1988) 2199.

[11] P. Gohil, et al., Proc. of the 14th IEEE/NPSS Symposium on Fusion Engineering, San Diego, 1991.

[12] C.C. Klepper, D.L. Hillis, M.R. Wade, et al., Rev. Sci. Instrum. 68 (1997) 400.

[13] R.A. Hulse, Nucl. Technol. Fusion 3 (1983) 259.

[14] R. Clark, J. Abdallah, D.E. Post, J. Nucl. Mater. 220-222 (1995) 1028.

[15] C. Hopf, A. von Keudell, and W. Jacob, Nucl. Fusion 42 (2003) L27. 